\title{
Adolescent Stress Confers Resilience to Traumatic Stress Later in Life: Role of
} the Prefrontal Cortex

Cotella, E.M ${ }^{1,3 *}$; Nawreen, $\mathrm{N}^{1,2 *}$; Moloney, R.D ${ }^{1}$; Martelle, S.E $\mathrm{E}^{1}$; Oshima, K.M ${ }^{1}$.; Lemen, $\mathrm{P}^{1}$.

$9 \quad *$ Both authors contributed equally

10 1. Dept. of Pharmacology \& Systems Physiology, University of Cincinnati, Cincinnati, Ohio

11 45237-0506, United States.

12 2. Neuroscience Graduate Program, University of Cincinnati, Cincinnati, Ohio 45237-0506,

13 United States.

14 3. Veterans Affairs Medical Center, Cincinnati, Ohio 45221, United States.

15 4. Department of Anesthesiology, Pain Research Center, University of Cincinnati Medical

16 Center, Cincinnati, $\mathrm{OH}$, United States.

18 Corresponding Author: James P. Herman james.herman@uc.edu Department of Pharmacology

19 \& Systems Physiology, University of Cincinnati, 231 Albert Sabin Way, Cincinnati, OH 45267-

20 0576, USA

23 Keywords: INFRALIMBIC CORTEX, POST-TRAUMATIC STRESS DISORDER, CHRONIC VARIABLE

24 STRESS, SINGLE PROLONGED STRESS, FEAR CONDITIONING INTRINSIC EXCITABILITY 
28 ABSTRACT: Stress during adolescence is usually associated with psychopathology later in life.

29 However, under certain circumstances, developmental stress can promote an adaptive

30 phenotype, allowing individuals to cope better with adverse situations in adulthood, thereby

31 contributing to resilience. The aim of the study was to understand how adolescent stress alters

32 behavioral and physiological responses to traumatic stress in adulthood. Sprague Dawley rats

33 were subjected to adolescent chronic variable stress (adol CVS) followed by single prolonged

34 stress (SPS) in adulthood. One week after SPS, animals were tested for acquisition, extinction,

35 extinction recall and reinstatement of auditory-cued fear conditioning, with neuronal

36 recruitment during reinstatement assessed by Fos expression. Patch clamp electrophysiology

37 was performed to examine physiological changes associated with resilience. We observed that

38 adol CVS blocked SPS-induced impairment of extinction learning (males) and enhancement fear

39 reinstatement (both sexes). SPS effects were associated with a reduction of infralimbic (IL)

40 cortex neuronal recruitment after reinstatement in males and increased engagement of the

41 central amygdala in females, both of which were also prevented by adol CVS. We explored the

42 mechanism behind reduced IL recruitment in male rats by studying the intrinsic excitability of IL

43 pyramidal neurons. SPS reduced excitability of IL neurons and prior adol CVS prevented this

44 effect, indicating that adolescent stress can impart resilience to the effects of traumatic stress

45 by modification of IL output in males. Overall, our study suggests that prior stress exposure can

46 limit the impact of a subsequent severe stress exposure in adulthood, effects that are mediated

47 by sex-specific modification of infralimbic and amygdala signaling. 


\section{Introduction:}

53 Understanding factors that affect the brain during adolescence has substantial health

54 relevance, given the onset of numerous affective conditions during this developmental period

55 (e.g., depression, anxiety disorders) (Andersen and Teicher, 2008; Kessler et al., 2005; Paus et

56 al., 2008). In general, chronic stress during development is associated with the emergence of

57 pathology, particularly when occurring during early life (de Kloet et al., 2005; Heim et al., 2008;

58 Oitzl et al., 2010; Riboni and Belzung, 2017; Tost et al., 2015). However, mild to moderate stress

59 during some development periods may also promote an adaptive response to adverse

60 situations later in life, contributing to stress resilience (Ordoñes Sanchez et al., 2021; Ricon et

61 al., 2012; Romeo, 2015; Schmidt, 2011; Southwick and Charney, 2012). Previous work from our

62 lab indictates that chronic variable stress (CVS) during adolescence can evoke specific effects

63 later in life that may determine either risk or resilience (Cotella et al., 2020, 2019). While the

64 mechanisms implicated in developmental vulnerability to stress dysregulation are widely

65 studied, resiliency after stress is poorly understood.

67 Memories acquired under stressful situations are usually strongly consolidated and can be

68 retrieved more easily than those acquired in neutral situations (Meir Drexler and Wolf, 2017).

69 Prior exposure to stress can further enhance the acquisition and/or expression of the fear

70 related behaviors (Blouin et al., 2016), processes linked to the prelimbic (PL) and infralimbic (IL)

71 divisions of the rodent medial prefrontal cortex (Giustino and Maren, 2015). Learned fear has

72 an obvious adaptive value, increasing the chance of survival in life threatening situations

73 (Giustino and Maren, 2015). However, traumatic experiences can lead to exaggerated and 
74 prolonged fear responses that can have pathological consequences, as seen in post-traumatic

75 stress disorder (PTSD). Here, individuals experience recurring episodes of involuntary memories

76 associated with an intense stress response, resulting in hyperalertness and avoidance of

77 situations that remind them of the traumatic event (Blouin et al., 2016; Sareen, 2014).

78 Interestingly, although there is a high chance of experiencing trauma in the population, only

79 about 7\% of people develop PTSD (Benjet et al., 2016; Kessler et al., 2005), suggesting that

80 resilience or vulnerability to development of PTSD may be determined by experiential and/or

81 genetic factors.

82

83 Rodents are widely used to study how stress affects learned fear memories. Stress-enhanced

84 fear models usually combine exposure to one or more stressors, with fear responses tested in a

85 conditioning paradigm (Blouin et al., 2016). One of the most widely-used and reproduced

86 models is the single-prolonged stress protocol (SPS) developed by Liberzon (Liberzon et al.,

87 1999, 1997). Exposure to SPS impairs extinction and extinction recall of a fear conditioned

88 response one week later (Knox et al., 2012b, 2012a; Kohda et al., 2007), comprising a late-

89 emerging enhancement of fear, as is characteristic of PTSD.

90

91 Prefrontal activity and neuronal intrinsic excitability is associated with stress resilience and

92 vulnerability (Kumar et al., 2014). For example, in humans the aberrent fear response in PTSD

93 is associated with ventromedial PFC (homolog to the rodent IL)(Öngür and Price, 2000)

94 hypoactivity and loss of top-down control over the amygdala (Milad et al., 2009). In rodents,

95 SPS also reduces neuronal activation in the IL (Piggott et al., 2019), which may play a role in the 
96 abnormal fear extinction deficits associated with SPS. Conversely, optogenetic drive of

97 the mPFC can promote stress resilience, and successful stress coping is linked to elevated mPFC

98 activation after social defeat stress (Covington et al., 2010) . However, the circuitry underlying

99 vulnerability and resilience are largely unknown (Russo et al., 2012).

100

101 In the present study we assess the impact of adolescent CVS on stress vulnerability or

102 resilience to subsequent SPS in adulthood. Our data indicate that the experience of stress

103 during adolescence blocks fear potentiation following SPS, leading to resilience, a phenomenon

104 that can be linked to descreases in intrinsic excitability of IL mPFC glutamatergic pyramidal

105 neurons.

106

107

108 Results:

109 Experiment 1: Cued conditioned response: Fig. 1.C-F illustrates the conditioned freezing

110 response throughout the different sessions of the fear conditioning paradigm in animals

111 that were submitted to chronic variable stress during adolescence (adol CVS) and later

112 subjected to single prolonged stress (SPS) in adulthood. Animals were submitted to a tone-

113 conditioned paradigm as shown in Fig 1.B. Fig 1.C-D show the effects for each phase of

114 paradigm evaluated.

115 Conditioning: None of the treatments had effects on the conditioning phase. There was an

116 interaction between adol CVS $\times$ SPS $\left(F_{(1,79)}=5.075, p=0.027\right)$ but no individual differences in the

117 Bonferroni test. The significant effect of time $\left(F_{(5,395)}=469.308, p<0.0001\right)$ confirmed conditioning 
118 of the response. There was main effect of $\operatorname{sex}\left(F_{(1,79)}=7.724, p=0.007\right)$, with Bonferroni

119 comparisons indicating a general higher expression of freezing in male rats.

120 3-day extinction: There were significant effects of SPS $\left(F_{(1,76)}=6.698, p=0.012\right)$ and time $\left(F_{(2,152)}=\right.$

$121475,661, p<0.0001)$ and an adol CVS $x$ SPS interaction $\left(F_{(1,76)}=7.414, p=0.008\right)$, with no effect of

122 sex. The CVS $x$ SPS post hoc analysis confirmed that, in general, SPS groups had higher freezing

123 levels compared to controls over the whole extinction procedure regardless of sex. When

124 performing planned comparisons by sex, only male rats showed statistical significant effects,

125 with the SPS group having higher freezing than the control group on all three days $(p<0.05)$ (the

126 CVS only group had enhanced freezing only on day $2(p<0.05))$. Prior adol CVS prevented the

127 SPS effects, as the double-hit group remained at control levels on all testing days and had

128 significantly less freezing than the SPS group on day $2(p<0.05)$. Sex differences were observed

129 only on day 3 , with SPS evoking higher freezing in male rats $(p<0.05)$.

130 Recall: The levels of extinction attained were stable for both sexes as tested in the recall phase.

131 In this case, five days after extinction, animals received a brief extra extinction session ( 3 tones)

132 to test for possible spontaneous recovery of the conditioned response and to corroborate that

133 the levels of freezing in all the groups were equal before reinstatement. We observed a

134 main effect of $\operatorname{sex}\left(F_{(1,76)}=7.958, p=0.006\right)$ with males expressing more freezing in general, and a

135 triple interaction sex $x$ adol CVS $\times$ SPS $\left(F_{(1,76)}=4.792, p=0.032\right)$ with no group differences emerging

136 for any individual Bonferroni comparison.

137 Reinstatement: We observed a significant adol CVS x SPS interaction $F_{(1,76)}=11.8095$,

$138 \mathrm{p}=0.001$. Posthoc comparison indicated that regardless of sex, the SPS group expressed higher

139 freezing than the control group ( $p<0.05$ respectively), while the double-hit group prevented the 
bioRxiv preprint doi: https://doi.org/10.1101/2021.03.16.435691: this version posted June 28, 2021. The copyright holder for this preprint (which was not certified by peer review) is the author/funder, who has granted bioRxiv a license to display the preprint in perpetuity. It is made available under aCC-BY-NC-ND 4.0 International license.

140 effect of SPS, remaining at control freezing levels and expressing significantly less freezing time

141 than the SPS group $(p<0.05)$. When analyzing the individual responses by sex

142 (planned comparisons), we observed that in female rats, only the SPS group differed from

143 control $(p<0.05)$. In the case of male rats, the SPS group had higher freezing than control

$144(p<0.05)$ and the adol CVS-SPS group $(p<0.05)$. 

available under aCC-BY-NC-ND 4.0 International license.

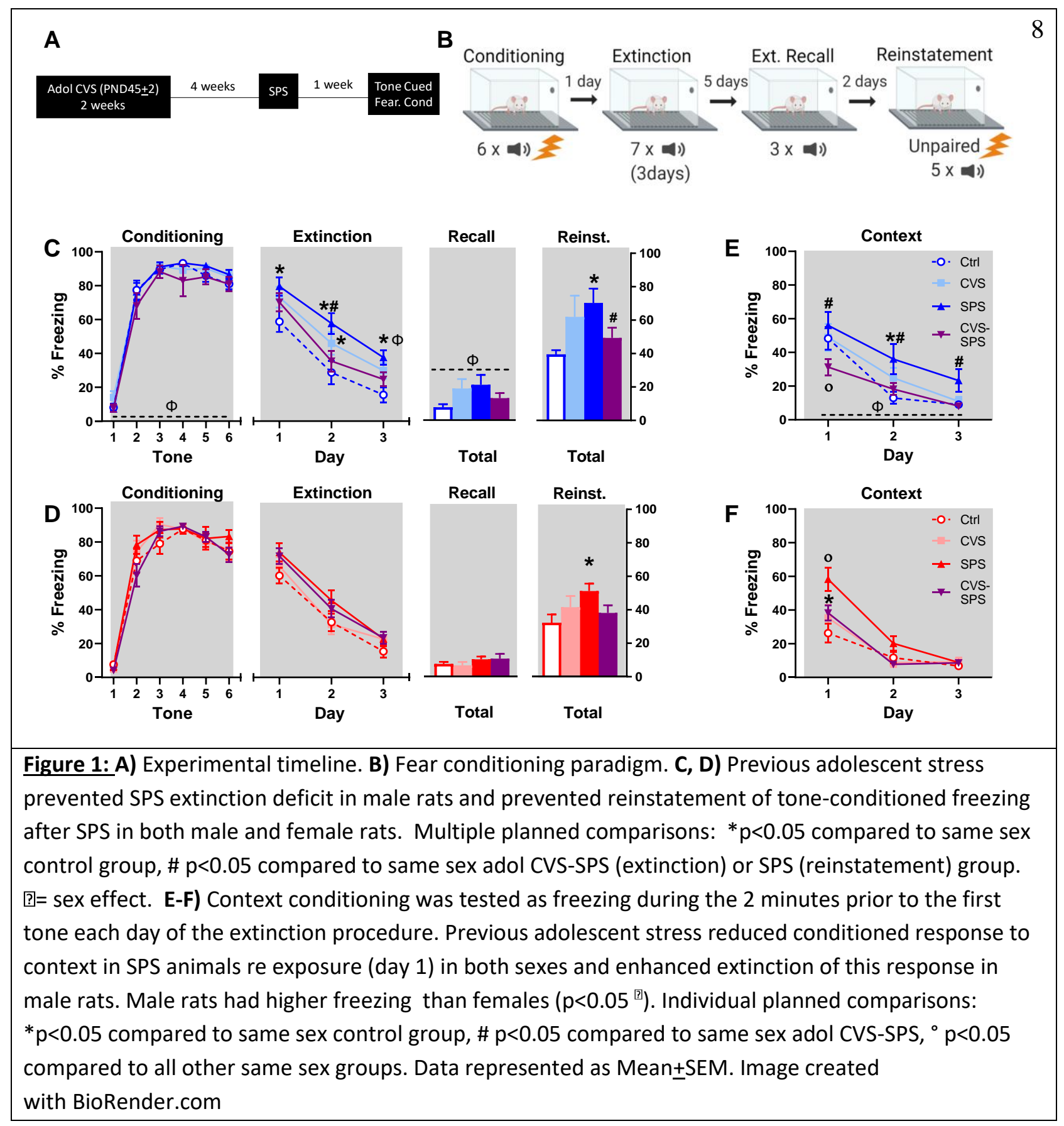

146 Context conditioned response: To quantify the conditioned response to the conditioning

147 context, we evaluated the freezing response evoked every day of the extinction procedure

148 before the first tone was presented and analyzed the progression over 3 days (Fig 1.E-F). We

149 observed a main effect of adol CVS $F_{(1,76)}=4.097, p=0.046$ and significant adol CVS $\times$ SPS

150 interaction $F_{(1,76)}=11.729, p=0.001$. The posthoc analysis indicated that animals subjected to SPS 
151 expressed higher freezing when re-exposed to the conditioning context compared to all the

152 other groups $\left(p<0.05\right.$ respectively). There was a sex effect $F_{(1,76)}=6.971, p=0.01$, with male rats

153 having more freezing time. There was also an effect of time $F_{(2,152)}=172.946, p<0.00001$,

154 indicating reduction of freezing to subsequent exposure. Finally, there was a time $x$ sex $x$

$155 \operatorname{SPS}\left(\mathrm{F}_{(2,152)}=9.253, \mathrm{p}=0.0002\right)$ interaction. Planned comparisons showed that male rats subjected

156 to SPS alone expressed higher freezing than the control group on day 2 while the group

157 subjected to the double-hit model of stress had less context freezing compared to all the other

158 groups on day 1 ( $p<0.05$ respectively). This difference was maintained against the SPS group on

159 the rest of the days tested $(\mathrm{P}<0.05$ respectively). In the case of females, SPS group had higher

160 freezing to the context than all the other groups on day 1 ( $p<0.05$ respectively) and

161 the adol CVS-SPS group also had more freezing compared to controls on that day $(p<0.05)$.

162

163 Fos expression after reinstatement: Figure 2 summarizes Fos activation (Fos immunoreactivity,

164 Fos-ir) in the mPFC and amygdala assessed following the reinstatement trial (90

165 min after the onset of the session). In the case of males, we observed a significant effect of SPS

166 in the infralimbic (IL) cortex of male rats, $F_{(1,16)}=7.706, p=0.0135$. Planned comparisons

167 confirmed that the SPS groups had significantly less Fos-ir than the control and CVS animals

168 ( $p<0.05)$, while the other groups did not differ from controls (Fig 2.A). In females, effects

169 of adol CVS and SPS were only observed in the central nucleus of the amygdala, particularly, in

170 lateral (CeL) but not medial subdivision of the central amygdala (CeM) (SPS $F_{(1,23)}=5.945$,

$171 p=0.0229$, adol CVS $\times$ SPS $\left.F_{(1,23)}=7.241, p=0.0130\right)$. Bonferroni's test confirmed that SPS

172 significantly increased neuronal recruitment $(p<0.05)$ and this was prevented in the double-hit

173 group $(p<0.05)$ (Fig 2.B). 


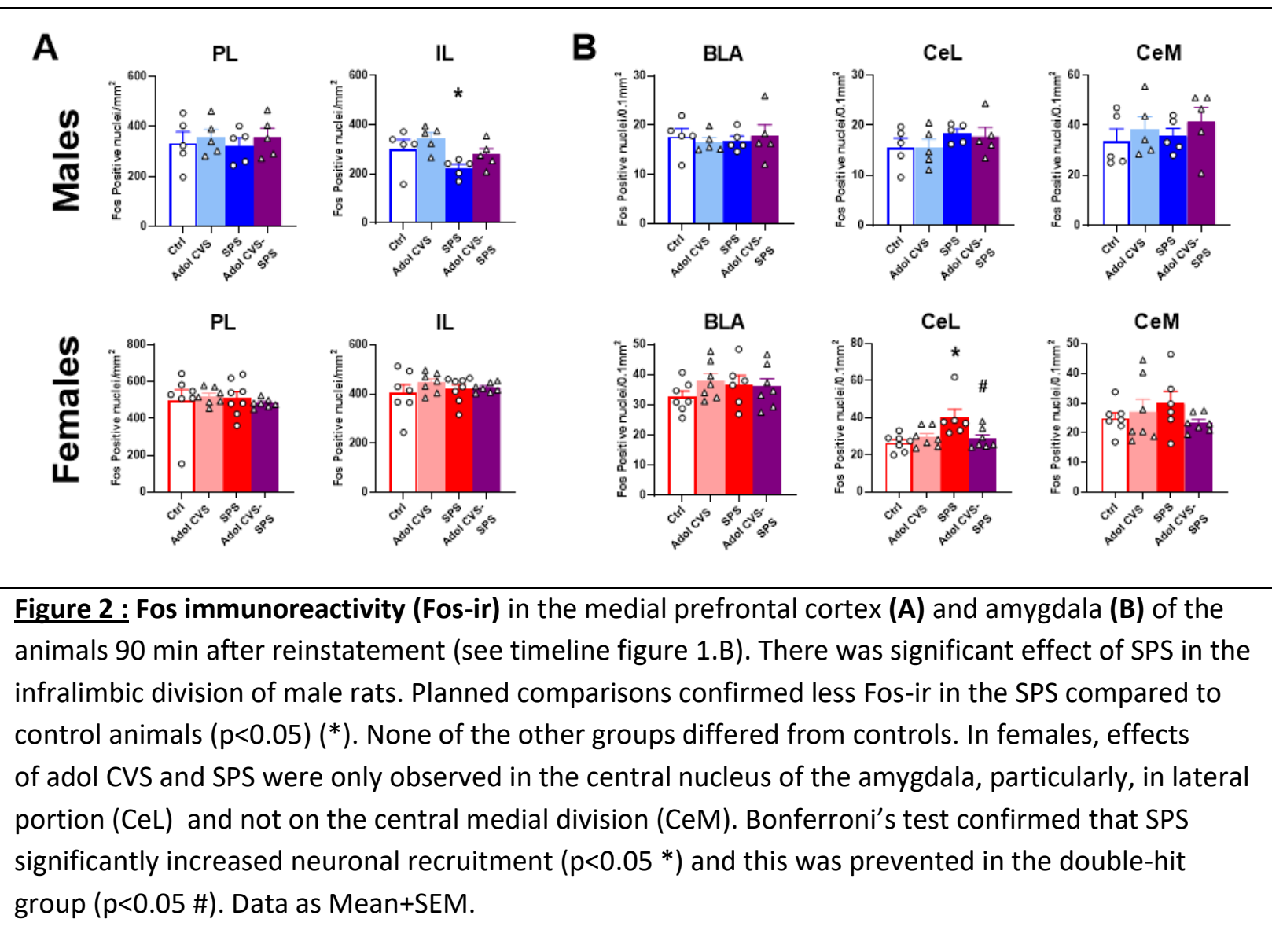

Experiment 3: Electrophysiology: We next investigated the potential cellular mechanisms

177 underlying how adolescent stress can prevent SPS-induced changes in fear behavior and Fos

178 activation in IL in male rats. Male rats were selected based on the clear effects of both SPS and

179 adolCVS/SPS on extinction learning, a process linked to the IL. We measured the intrinsic

180 membrane properties and firing frequency of IL pyramidal neurons in layer $\mathrm{V}$, the major source

181 of subcortical output from the IL (Baker et al., 2018). We found that prior experience of adol

182 CVS prevented SPS-mediated changes in intrinsic excitability of IL pyramidal neurons. There was

183 a significant main effect of SPS $\left(F_{(1,99)}=32.3, p<0.0001^{\text {a (table } 1)}\right)$ and adol CVS $\left(F_{(1,99)}=8.5\right.$, 
$184 p=0.005^{a}$ ) on rheobase (Fig.3D). SPS significantly increased rheobase compared to the control

185 group $(p<0.05)$, which was prevented by prior adol CVS ( $<<0.05$ compared to SPS). There was a

186 significant main effect of SPS $\left(F_{(1,98)}=41.96, p<0.0001^{b}\right)$, adol CVS $\left(F_{(1,98)}=21.7, p=0.0002^{b}\right)$ and a

187 significant adol CVS X SPS interaction $\left(F_{(1,98)}=6.7, p=0.01^{b}\right)$ on membrane resistance (Fig.3E).

188 Bonferroni's test indicated that SPS significantly decreased membrane resistance $(p<0.05)$,

189 which was prevented by prior adol CVS ( $p<0.05$ compared to SPS). Statistical analysis for

190 membrane resistance was performed on log transformed data. There were significant main

191 effects of SPS $\left(F_{(1,92)}=19, p<0.0001^{c}\right)$, adol CVS $\left(F_{(1,92)}=14.3, p=0.0003^{c}\right)$ and a significant adol CVS

$192 \times$ SPS interaction $\left(F_{(1,92)}=5.0, p=0.02^{c}\right)$ on action potential $(A P)$ threshold (Fig 3F). Bonferroni's

193 test indicated that SPS significantly increased AP threshold compared to controls $(p<0.05)$, with

194 prior adol CVS preventing the effect ( $p<0.05$ compared to SPS). There were main effects of SPS

$195\left(F_{(1,97)}=20, p<0.001^{d}\right)$, adol CVS $\left(F_{(1,97)}=25.9, p<0.0001^{d}\right)$ and significant adol CVS $x$ SPS interaction

$196\left(F_{(1,97)}=6.5, p=0.01^{d}\right)$ on action potential amplitude (Fig.3G). Bonferroni's test indicated that SPS

197 significantly lowered AP amplitude compared to controls $(p<0.05)$, and prior experience adol

198 CVS prevented it ( $p<0.05$ compared to SPS). There was a significant effect of SPS $\left(F_{(1,97)}=8.3\right.$,

$\left.199 \mathrm{p}=0.005^{\mathrm{e}}\right)$ and adol CVS $\left(\mathrm{F}_{(1,97)}=42.2, \mathrm{p}<0.0001^{\mathrm{e}}\right)$ on AP50 (Fig. 3H). Planned comparisons

200 indicated a decrease in AP50 following SPS compared to control $(p<0.05)$ and prior adol CVS

201 prevented that effect ( $p<0.05$ compared to SPS). Increase in AP50 was also observed following

202 adol CVS only ( $p<0.05$ compared to control). Resting membrane potential (RMP) was unaltered

203 among the groups (Fig.3I). 2 way ANOVA revealed no significant main effect of SPS $\left(F_{(1,95)}=1.3\right.$,

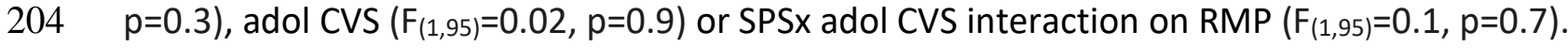


205 Membrane capacitance was unaltered among groups (Fig.3J) indicating the treatments did not

206 likely affect cell size. 2 way ANOVA of membrane capacitance revealed no significant main

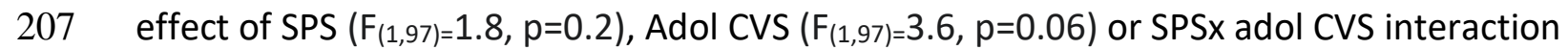

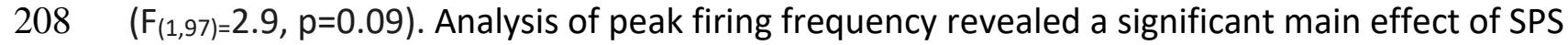

$209\left(F_{(1,36)}=13.4, p=0.0008^{h}\right)$. Planned comparisons indicated that SPS significantly reduced peak

210 firing frequency compared to controls $(p<0.05)$, whereas the prior adol CVS+SPS group did not

211 differ from the control group (Fig.3K). Figure 3L shows representative traces of action potentials

212 evoked by 20pA current injection for the respective groups. Together these data indicate that

213 prior experience of adolescent stress is able to prevent the reduction in intrinsic excitability and

214 firing rate of IL layer V pyramidal neurons following SPS. 


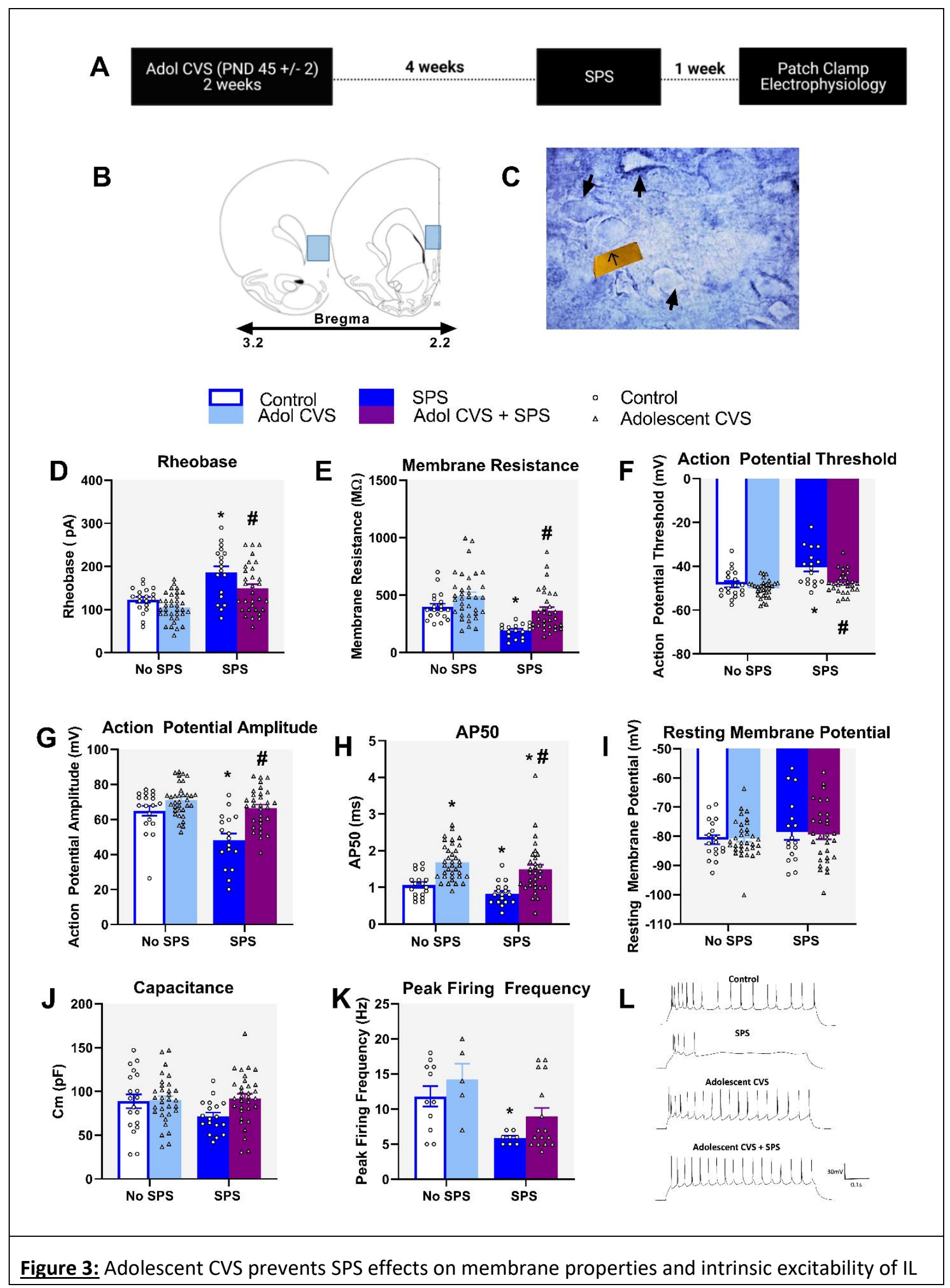


pyramidal neurons. (A) Experimental timeline; (B) Schematic of coronal brain sections through PFC where recordings were performed, blue boxes indicate infralimbic region of the PFC; (C) Pyramidal neurons were identified based on somal morphology and presence of prominent apical dendrite . Arrows indicate pyramidal neurons; SPS increased rheobase (D) and decreased membrane resistance (E), whereas prior experience of adol CVS was able to prevent these effects. SPS increased the threshold for action potential (AP) firing (F) and decreased AP amplitude (G), both of which were prevented by prior adol CVS. SPS also reduced the duration of AP (AP 50), which was also blocked by prior adol CVS. It should be noted that adol CVS alone increased AP duration (H). Finally, adol CVS was also able to attenuate the reduction in peak firing frequency observed following SPS (K). No changes in resting membrane potential (I) or membrane capacitance (J) were observed. (L) demonstrates representative traces of action potentials evoked by $20 \mathrm{pA}$ current injection for the respective groups; For $\mathrm{D}, \mathrm{H}, \mathrm{K}^{*}$ and \# represents planned comparison effects compared with control and SPS respectively. For $\mathrm{E}, \mathrm{F}$ and $\mathrm{G}^{*}$ and \# represents post hoc Bonferroni effects compared with control and SPS respectively. Data represented as Mean+SEM.

\section{Discussion}

218 Our results strongly suggest that prior experience with stress during adolescence can evoke a

219 resilient phenotype in the adult, characterized by the prevention of the effects of SPS in a fear

220 conditioning paradigm and on IL pyramidal cell excitability. Our data indicate that the

221 adaptations resulting from exposure to chronic stress during adolescence buffer the behavioral

222 impact of a model of traumatic stress in adulthood, blocking known effects of SPS on

\section{3 subsequent fear potentiation.}


224 While prior CVS is able to block enhancement of reinstatement in both sexes, it appears to do

225 so by distinct neuronal mechanisms. Reversal of SPS-induced resinstatement was accompanied

226 by IL hypoactivity in males and CeL recruitment in females, suggestion differential engagement

227 of cortical regions regulating extinction (males) vs. fear expression (females) across the sexes.

228 Notably extinction deficits were only observed in males, consistent with the known role of the

229 IL in extinction of conditioned fear. A role for the IL in CVS-induced resilience in males is further

230 supported by hypoactivity of layer V pyramidal cells following SPS, which is blocked by prior

231 adolescent CVS (Figure 4).

232

233 Stress during development is generally thought to evoke negative behavioral effects later in life

234 (Begni et al., 2020; Bourke and Neigh, 2011; Cotella et al., 2020, 2019; Green et al., 2013;

235 Negrón-Oyarzo et al., 2014; Wilkin et al., 2012; Wulsin et al., 2016). However, prior studies also

236 support the ability of adolescent stress to confer stress resilience in adulthood, using a number

237 of stress models, e.g., intermittent predator stress (Kendig et al., 2011) and predictable chronic

238 mild stress (PCMS) (Suo et al., 2013). Adolescent PCMS enhances extinction and prevents

239 reinstatement and spontaneous recovery in a fear conditioning model evaluated immediately

240 and one week following PCMS (Deng et al., 2017). Consistent with our results, these suggest

241 that adolescent stress enhancement of resilience endures well beyond the time of exposure.

242 The impact of adolescent stress differs thatt of stress imposition earlier in life, where the data

243 generally report detrimental effects of stress (Johnson and Casey, 2014; Lukkes et al., 2009;

244 McEwen, 2007; Vyas et al., 2002; Yee et al., 2012). 
246 Although some authors proposed that the resilient phenotype is promoted by the predictability

247 of the stressors (Deng et al., 2017), the general unpredictable nature of CVS suggests that the

248 resilience mechanism is independent of response habituation In our study, the adol CVS

249 paradigm employs exposure to swim and restraint, albeit in an isolated and time-attenuated

250 fashion relative to SPS. Nonetheless, the length and consecutive application of the stressors

251 during SPS represents a distinct and intense unpredictable experience. This contention is

252 supported by a recent report demonstrating behavioral resilience to SPS using exposure to

253 completely different stressors during adolescence (Chaby et al., 2020).

254 Timing combined with stressor modality seem to be an important factor as well. In this sense,

255 prior work indicates adult resilience even after a single intense stressor protocol at PND37

256 (Moore et al., 2014) or following 3 days of predator related stressors at PND33-35 (Chaby et al.,

257 2020). In contrast, a 3-day pre-pubertal exposure to variate stressors failed to attenuate

258 exaggeration of fear responses in adulthood (Tsoory et al., 2010; Yee et al., 2012), indicating

259 that developmental timing is critical for establishment of resilience. 
Hypoactivity of the medial PFC is observed in several mental health disorders, including PTSD
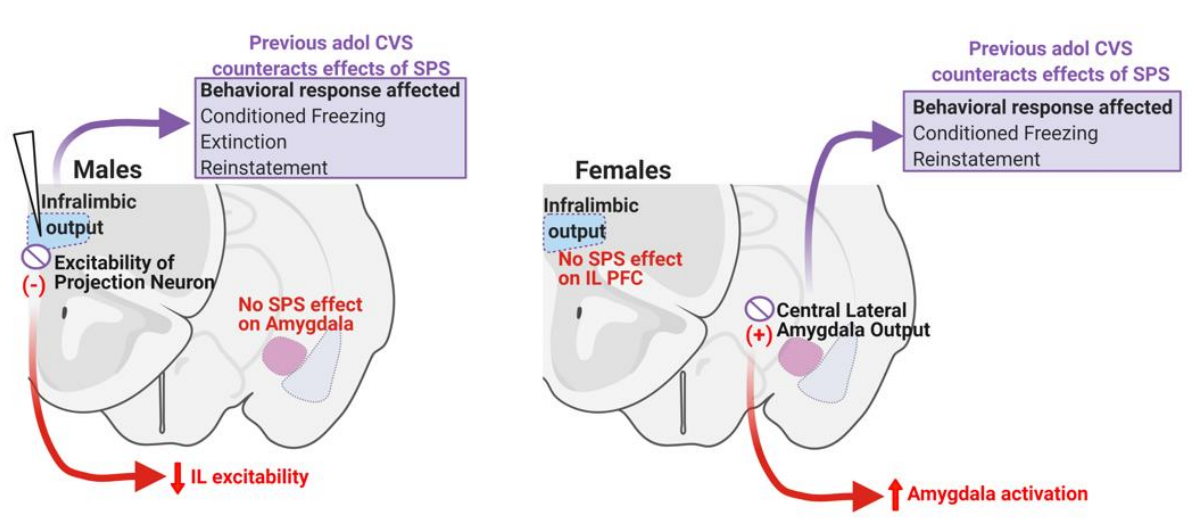

Adol CVS + SPS Effect

SPS effect

Fig 4: Summary of the effects observed. Prior exposure to adol CVS prevented the behavioral outcomes evoked by SPS in male and female rats. In the case of males, it also counteracted the effects of SPS on infralimbic excitability, indirectly inferred by Fos staining after reinstatement and confirmed by electrophysiology on pyramidal neurons from layer V. These central effects of adol CVS on SPS outcomes highlight the relevance of the infralimbic cortex as a hub for neurodevelopmental plasticity that could lead to resilience to stressful events in adulthood. In female rats, the absence of SPS effects in neuronal recruitment in the infralimbic cortex, accompanied by an increase of it in the central lateral division of the amygdala suggests a marked difference in the circuitry affected by SPS in both sexes. This points out to a possible mechanism involving excitability in that area that has yet to be confirmed.

(Hains and Arnsten, 2008). Results from our group and others indicate that stress during

264 adolescence reduces neuronal recruitment (Fos expression) to adult stressors in the mPFC

265 (Cotella et al., 2020, 2019; Ishikawa et al., 2015). In humans, PTSD has been associated with a

266 reduction in prefrontal drive, leading to abnormal extinction of conditioned fear (Milad et al.,

267 2009, 2006, 2005; Rauch et al., 2006). Similarly, reduced IL mPFC activity following SPS in male

268 rats may underlie abnormal extinction of fear responses (Piggott et al., 2019). Consistent with

269 these data, our results indicate reduced IL recruitment following SPS in male rats accompanied

270 by higher freezing during extinction and reinstatement. The reduced engagement of the IL in 
271 response to conditioned cues during the reinstatement procedure in the SPS male group also

272 suggests a possible reduction of IL activity occurring during the prior extinction procedure,

273 which would explain the impairment of extinction learning previously observed only in males

274 rats.

275 Neurons in the mPFC are specifically activated during stressful situations and modulate their

276 responses to subsequent exposure to the same stressor experience (Jackson and Moghaddam,

277 2006), thus playing a critical role in eliciting adaptive responses to aversive stimuli (Milad and

278 Quirk, 2002). Modification of PFC responses to the same stimulus can be mediated through

279 altered glutamatergic or dopaminergic drive onto the mPFC projection neurons (Bagley and

280 Moghaddam, 1997; Jackson and Moghaddam, 2004). Adolescent social defeat decreases adult

281 NMDA receptor expression in the IL PFC, and also reduces freezing to fear conditioning (Novick

282 et al., 2016). Thus, the enhanced excitability we observed in SPS rats with prior history of adol

283 CVS might be a long-term adaptation to the reduced excitatory drive that may occur following

284 adol CVS.

285 Intrinsic membrane properties play an important role indetermining the prefrontal

286 excitatory/inhibitory balance, as they directly shape neuronal output by influencing the

287 probability of a neuron firing an action potential in response to synaptic inputs (Anderson et

288 al., 2019). Our data indicate that the IL intrinsic excitability changes do not manifest at baseline

289 conditions under adol CVS alone, consistent with prior work in mice resilient to social defeat

290 (Friedman et al., 2014; Han and Nestler, 2017). Thus it is possible that prior adol CVS may serve

291 to prime the pyramidal cells to react appropriately when faced with the second hit of SPS,

292 compensating for reduced excitability associated with SPS. The exact mechanism underlying the 
293 altered excitability of IL pyramidal neurons observed in our study is yet to be determined.

294 Possibilities include lasting alteration in ion channel function (e.g., G protein-gated inwardly

295 rectifying $\mathrm{K}+$ channels) (Anderson et al., 2019; Hearing et al., 2013) or modulation on

296 excitability by hyperpolarization-activated cyclic nucleotide-gated channels (Shah, 2014).

297 Further work is needed to identify the specific ionic mechanisms by which adolescent stress can

298 protect against future stressors during adulthood. (Matovic et al., 2020).

\section{Conclusion:}

301 Our results support the idea that certain combinations of stressful situations during

302 adolescence can be beneficial, evoking resilience to stress in adult life. We propose that, in

303 rats, chronic variable stress during late adolescence determines differential activation or

304 recruitment of the IL in response to intense stress in adulthood. This rearrangement of

305 prefrontal activity results in a phenotype that is resilient to stress-enhanced fear learning,

306 reducing contextual response, facilitating extinction and preventing reinstatement of the fear

307 conditioned response following trauma, findings that may lend insight into under standing

308 susceptibility of resilience toPTSD. Furthermore, our data guide our next steps to understand

309 the sex specific effects in behavioral resilience following adolescent stress that pointed to

310 fundamental sex differences in stress reactive brain regions and their involvement in

311 resiliencelt would be important as well to determine which stressor type might result in a

312 positive emotional valence and whether that ultimately evokes a resilience response. For

313 example, the exercise (swim) or social component (crowding) of the adolescent CVS regimen

314 might help individuals cope with subsequent stress in adulthood (Herring et al., 2010; Ozbay et 
315 al., 2007). The next challenge is to find the most efficient developmental triggers for the

316 generation of resilience to the effects of adult stress, possibly including positive developmental

317 interventions, with the goal of reducing the incidence of stress-related affect conditions,

318 including PTSD.

$320 \quad$ Materials and Methods

321 Animals: Male and female Sprague Dawley rats were bred in-house, weaned at postnatal day

32221 (PND21) and pair-housed in standard clear cages $(20 \mathrm{~cm}$ height $\times 22 \mathrm{~cm}$ width $\times 43 \mathrm{~cm}$ length)

323 under a $12 \mathrm{~h}$ light/ $12 \mathrm{~h}$ dark cycle (lights on at 7:00 am), at constant room temperature $(23+2$

$\left.324{ }^{\circ} \mathrm{C}\right)$, with ad libitum access to food and water. All tests were performed during the light cycle,

325 between 09:00 AM and 2:00 PM. All procedures and care performed in the animals were

326 approved by the University of Cincinnati Institutional Animal Care and Use Committee. 


\section{Adolescent chronic}

329 (adol CVS): After

330 animals, a cohort

\begin{tabular}{|l|}
\hline $1 \mathrm{~h}$ shaker stress $(100 \mathrm{rpm})$ \\
\hline $1 \mathrm{~h}$ cold room $\left(4^{\circ} \mathrm{C}\right)$ \\
\hline 30 min hypoxia exposure $(8 \%$ O2 and $92 \% \mathrm{~N} 2)$ \\
\hline 30 min restraint in plexiglass adjustable cylinder \\
\hline 10 min group cold swim $\left(17 \pm 1^{\circ} \mathrm{C}\right)$ \\
\hline 20 min group warm swim $\left(32+1^{\circ} \mathrm{C}\right)$ \\
\hline
\end{tabular}

variable stress

weaning the

was randomly

331 assigned to 4 experimental groups Control (No CVS - No SPS), Adol CVS (only chronic stress in

332 adolescence), SPS (only single prolonged stress in adulthood) and CVS-SPS or double-hit group

333 (adol CVS + SPS in adulthood). The remaining animals from the litter were assigned to control

334 and adol CVS groups for the evaluation in the novel object test and Morris water maze to assess

335 general cognitive function. No more than 2 littermates were included in each experimental

336 group. Rats were subjected to our standard 14 days CVS protocol during late adolescence (PND

$33745 \pm 2$ ) following prior work from our group (Jankord et al., 2011). The CVS paradigm included a

338 set of unpredictable variable stressors applied twice daily (AM and PM, see table). In addition,

339 animals were exposed to overnight stressors every two days: 1) individual housing, 2) social

340 crowding (six rats per cage). Control animals were maintained in the same room and only

341 handled for normal husbandry. Except for overnight stressors, all the procedures related to CVS

342 were performed in a different room. Following CVS, animals were allowed to recover for 4

343 weeks to be then subjected to the single prolonged stress (SPS) protocol evaluated during

344 adulthood. The timeline of the experiment is shown in Fig. 1.

348 Single prolonged stress (SPS): A groups of rats subjected to adolescent CVS (and their

349 respective controls) were subjected to SPS 4 weeks after the end of CVS. For this, starting at 
9:00 AM, animals were restrained for 2 hours in plexiglass adjustable cylinders dimensions

$35120 \mathrm{~cm} \times 7 \mathrm{~cm}$. Immediately after $2 \mathrm{~h}$ elapsed, they were subjected to 20 minutes of group swim

$352\left(25+2^{\circ} \mathrm{C}\right)$ in a bucket with dimensions $50 \mathrm{~cm} \times 33 \mathrm{~cm}$. Immediately after they were retrieved

353 from the water and the excess of water was eliminated from their coat, they were allowed to

354 recover for 15 minutes in their home cage with their cage mate. Next, rats were placed into a

355 glass chamber where they were exposed to ether vapor until loss of consciousness (loss of

356 righting position and palpebral reflex). Immediately after unconsciousness was confirmed they

357 were placed in a cage with clean bedding material and returned to their housing room. SPS was

358 administered in a novel experimental room. After SPS, animals remained undisturbed for a

359 week (the usual time required to observe SPS effects (Knox et al., 2012b; Kohda et al., 2007;

360 Wen et al., 2015)). Control rats remained in the housing room during the application of SPS and

361 were only subjected to cage change during that time.

362

363 Cued Fear Conditioning Paradigm: A week after SPS all groups were subjected to an auditory

364 tone cued fear conditioning protocol to evaluate the performance of the animals during the

365 conditioning, extinction, and reinstatement sessions. Behavioral evaluation occurred between

366 8:30 AM - 2:00 PM. Conditioning: animals were allowed to explore the conditioning chamber

367 for $3 \mathrm{~min}$, after which they were exposed to a 20s auditory tone (conditioned stimulus, CS), co-

368 terminating with a $0.5 \mathrm{~s}, 0.45 \mathrm{~mA}$ shock (unconditioned stimulus, US), with an inter-trial interval

369 (ITI) of 120s. The tone-shock pairings were repeated six times. Data were presented as \%

370 Freezing over CS time (20s). Extinction: $24 \mathrm{~h}$ after conditioning animals were subjected to 3

371 consecutive days of extinction in which they were exposed to 7 repetitions of the CS with 120 s 
$372 \mathrm{ITI}$ in the same conditioning chambers. Data were presented as Total \% Freezing over the 3 days

373 of the extinction procedure, corresponding to the cumulative $\%$ of freezing expressed over the

374 cumulative CS time during the whole extinction session (7x20s: 140s). Recall test: 5 days after

375 the last extinction session animals were placed in the conditioning chambers and exposed to 3

376 repetitions of the CS, with 120 s ITI with the purpose of evaluating spontaneous recovery of the

377 conditioned response. Data were presented as Total \% Freezing calculated as cumulative \% of

378 freezing expressed over the cumulative CS time during the session (3x20s: 60s).

379 Reinstatement: $48 \mathrm{~h}$ after the recall session animals were exposed to a reinstatement session

380 in the same conditioning chambers, consisting of 3 min of chamber exploration followed by 1

381 unpaired shock (US) (0.45 mA, 0.5s). After a delay of 120 s animals were exposed to 5

382 repetitions of the CS (120s ITI). Data were expressed as total \% Freezing during tones after

383 unpaired shock, Total \% Freezing over the cumulative duration of CS time $(5 \times 20 s=100 s)$. Rats

384 were euthanized 90 min after the onset of the session to obtain brains for

385 immunoshitochemistry.

386 Context fear conditioning test: As a way of quantifying the conditioned response to the

387 context, we evaluated the initial freezing response exerted every day of the extinction

388 procedure before the first tone was presented and analyzed the progression of this response

389 over the 3 days. Data were expressed as \% Freezing over the initial pre-tone exploration time

390 (120s).

391 The conditioned response evaluated was freezing behavior, considered as general absence of

392 movement, which was scored using a video tracking system (EthovisionXT-Noldus). We did not

393 consider other behaviors as, in our set up, animals do not show conditioned darting or any 
394 other escape related behaviors, with both sexes consistently exhibiting freezing in response to

395 the tone. 90 minutes after reinstatement rats were euthanized to obtain their brains for

396 immunodetection of Fos, a marker of neuronal activation. Results were analyzed considering

397 sex as a variable.

398 Group composition fear conditioning experiment: The experiment was originally designed with

39910 male rats per group and 12 female rats per group. A male rat assigned to CVS died of

400 unknown reasons during the first week of CVS resulting in a $\mathrm{n}$ of 9 for that group. A spare rat

401 was added to that home cage to avoid having to exclude the house mate of the lost individual

402 due to isolation. Later, on extinction day 2, there was a malfunction of the conditioning

403 chambers which resulted in shocking the animals as soon as the session started. This resulted in

404 the exclusion of the 3 animals run during that session (2 controls, 1 CVS). Therefore beginning

405 day 2 of the paradigm, the $\mathrm{n}$ for control and CVS males was 8.

406 In the case of females, we originally planned to include 12 females per group, nevertheless, due

407 to a mistake during the day of SPS, 1 cage of CVS animals was wrongfully submitted to SPS in

408 lieu of a cage without CVS planned to get SPS. That resulted in an imbalance in the final number

409 of animals per group: Control and CVS-SPS groups had $n=14$ and CVS and SPS groups had $n=10$.

410 The experimental timeline is shown in Figure 1.

411 Immunohistochemistry: Rats were euthanized with an overdose of sodium pentobarbital and

412 immediately transcardially perfused with $0.9 \%$ saline followed by $4 \%$ paraformaldehyde in

413 0.1M phosphate buffer (PBS), $\mathrm{pH}$ 7.4. Brains were post-fixed in $4 \%$ paraformaldehyde at $4{ }^{\circ} \mathrm{C}$

414 for $24 \mathrm{~h}$, then transferred to $30 \%$ sucrose in $0.1 \mathrm{M}$ PBS at $4{ }^{\circ} \mathrm{C}$ where they were kept until tissue

415 processing. Brains were sliced into serial $35 \mu \mathrm{m}$ coronal sections using a freezing microtome 
$416\left(-20^{\circ} \mathrm{C}\right)$. Sections were collected into multi-well plates containing cryoprotectant solution (30\%

417 Sucrose, $1 \%$ polyvinyl-pyrolidone (PVP-40), and $30 \%$ ethylene glycol in 0.1M PBS). For

418 immunolabeling, sections were washed $6 \times 5$ min in $0.01 \mathrm{M}$ PBS at room temperature (RT). After

419 being rinsed, sections were incubated with $1 \%$ sodium borohydride in $0.1 \mathrm{M}$ PBS for $30 \mathrm{~min}$ at

420 RT. After rinsing $6 \times 5$ min 0.1 M PBS, they were incubated in $3 \%$ hydrogen peroxide diluted in

$421 \quad 0.1 \mathrm{M}$ PBS for $20 \mathrm{~min}$. Subsequently, brain slices were rinsed $6 \times 5$ min and $4 \times 15 \min$ in $0.1 \mathrm{M}$ PBS

422 and then incubated in blocking solution (4 \% normal goat serum (NGS), $0.4 \%$ TritonX-100, $0.2 \%$

423 bovine serum albumin (BSA) in 0.1M PBS, $2 \mathrm{~h}$ at RT. Sections were then incubated with c-Fos

424 rabbit polyclonal antibody (1:1000, Santa Cruz, sc-52) in blocking solution, overnight at RT. The

425 next day, sections were rinsed ( $3 \times 5 \mathrm{~min}$ ) in $0.1 \mathrm{M} \mathrm{PBS}$ at RT, followed by incubation with

426 secondary antibody (biotinylated goat anti-rabbit, 1:400; Vector Laboratories, BA1000) in

427 blocking solution at RT for $1 \mathrm{~h}$. Sections were again rinsed ( $3 \times 5 \mathrm{~min})$ in $0.1 \mathrm{M}$ PBS and then

428 reacted with avidin-biotin horseradish peroxidase complex (1:800 in 0.1 M PBS; Vector

429 Laboratories) for $1 \mathrm{~h}$ at RT. Sections were then rinsed $(3 \times 5 \mathrm{~min})$ in $0.1 \mathrm{M}$ PBS and then

430 developed with a 8 min incubation in DAB-Nickel solution: $10 \mathrm{mg}$ 3,3'-diaminobenzidine (DAB)

431 tablet (Sigma, DF905), $0.5 \mathrm{ml}$ of a $2 \%$ aqueous nickel sulfate solution, 20 ul of $30 \%$ hydrogen

432 peroxide in $50 \mathrm{ml}$ of $0.1 \mathrm{M}$ PBS. Sections were finally washed in PBS, mounted on superfrost

433 slides (Fisherbrand, Fisher), allowed to dry, dehydrated in xylene, and then coverslipped in DPX

434 mounting medium (Sigma). Sections from 5 to 7 brains per experimental group were processed.

435 For analysis, we counted 3 bilateral sections from equivalent coordinates covering the anterior,

436 medial and posterior portions of the prefrontal cortex (PFC), nuclei in the amygdala: central

437 amygdaloid nucleus (CeAm), medial amygdaloid nucleus (MeAm), lateral amygdaloid nucleus 
438 (LAm) and basolateral amygdala (BLA). Each brain region limit and coordinates were defined

439 following a brain atlas (Paxinos and Watson, 2007). The number of Fos positive nuclei was

440 counted with a semiautomatized method using ImageJ software (National Institutes of Health,

441 Bethesda, MD). Counts of Fos immunoreactive cells were obtained from each area of interest

442 using the Analyze Particle tool, using a defined common level of background intensity, nuclei

443 circularity and size (previously validated manually). Once the number of Fos positive nuclei was

444 determined in each section, the relative density of the population of immunopositive cells was

445 calculated by dividing this number by the area measured in each case. Considering that the

446 number of animals used simultaneously in the study makes it logistically complicated to process

447 all the tissue at the same time or separating in batches and obtain homogenous immune

448 staining, we decided to prioritize the within sex results for the Fos quantification and tissue

449 from male and female rats was processed and analyzed independently.

452 Electrophysiology: Following the same timeline as the behavioral studies, whole-cell patch

453 clamp recordings were obtained from layer V pyramidal neurons in the IL PFC. Details of slice

454 preparation and electrophysiology recordings from adult PFC are given below.

456 Slice Preparation: Rats were sacrificed 7 days post SPS. Animals were deeply anesthetized with

457 sodium pentobarbital ( $390 \mathrm{mg} / \mathrm{kg}$, Fatal-Plus) and decapitated. A warm slicing protocol was

458 used to prepare healthy adult rat brain slices as previously described (Ting et al., 2014). Brains

459 were quickly isolated and dura matter carefully removed before removing the cerebellum. The 
460 brain was then immediately glued to a cutting stage immersed in NMDG solution (92 mM

$461 \mathrm{NMDG}, 2.5 \mathrm{mM} \mathrm{KCl}, 1.2 \mathrm{mM} \mathrm{NaH}_{2} \mathrm{PO}_{4}, 30 \mathrm{mM} \mathrm{NaHCO}_{3}, 20 \mathrm{mM}$ HEPES, $25 \mathrm{mM}$ glucose, $5 \mathrm{mM}$

462 sodium ascorbate, $2 \mathrm{mM}$ thiourea, $3 \mathrm{mM}$ sodium pyruvate, $10 \mathrm{mM} \mathrm{MgSO}_{4}$, and $0.5 \mathrm{mM} \mathrm{CaCl}$ )

463 at a temperature of $34-36^{\circ} \mathrm{C}$ and continuously bubbled with $95 \%$ oxygen and $5 \%$ carbon-

464 dioxide. Coronal slices containing the mPFC were sectioned at $300 \mu \mathrm{m}$ thickness using a

465 vibrating microtome (7000smz-2; Campden Instruments, Lafayette, IN) with ceramic blades

466 (Campden Instruments) at an advance speed of $0.03 \mathrm{~mm} / \mathrm{s}$. Vertical vibration of the blade was

467 manually tuned in accordance with the user manual, and was set to $0.1-0.3 \mu \mathrm{m}$. Bath

468 temperature was kept within the desired range of $34-36^{\circ} \mathrm{C}$, by adding warm or cold water into

469 the external chamber of the slicer, and was monitored throughout the cutting procedure with a

470 conventional mercury/glass thermometer. The slices were allowed to recover for 1 hour in

471 oxygenated NMDG solution at $34-36^{\circ} \mathrm{C}$. At the end of recovery, slices were transferred to a

472 chamber containing oxygenated artificial CSF solution (125 mM NaCl, $2.5 \mathrm{mM} \mathrm{KCl}, 25 \mathrm{mM}$

$473 \mathrm{NaHCO}_{3}, 1 \mathrm{mM} \mathrm{NaH}_{2} \mathrm{PO}_{4}, 25 \mathrm{mM}$ glucose, $1 \mathrm{mM} \mathrm{MgCl}, 2 \mathrm{mM} \mathrm{CaCl}$ ) for at least 30 minutes at

474 room temperature after which the slices were ready for in vitro patch clamp recordings for the

475 next 1-6 hours.

476 Electrophysiological recording: Brain slices were transferred to a submersion-type recording

477 chamber (RC-22; Warner Instruments, Hamden, CT) and mounted onto the stage of an upright

478 microscope (BX51WI, Olympus, Center Valley, PA). Slices were then perfused at a flow rate of

$4792-4 \mathrm{ml} / \mathrm{min}$ with oxygenated aCSF at $34-36^{\circ} \mathrm{C}$. Patch electrodes were constructed from thin-

480 walled single-filamented borosilicate glass $(1.5 \mathrm{~mm}$ outer diameter; World Precision

481 Instruments) using a microelectrode puller (P-97; Sutter Instruments, Novato, CA) and filled 
482 with an intracellular solution (130 mM K-gluconate, $10 \mathrm{mM} \mathrm{KCl,} 10 \mathrm{mM}$ HEPES, $10 \mathrm{mM}$ sodium

483 phosphocreatine, $4 \mathrm{mM} \mathrm{MgATP}$, and $0.3 \mathrm{mM} \mathrm{Na}-\mathrm{GTP}, \mathrm{pH} 7.2,295-300 \mathrm{mOsm})$. Pipette

484 resistances ranged from 4 to $6 \mathrm{M} \Omega$, and seal resistances were $>1 \mathrm{G} \Omega$.

485 Whole-cell patch clamp recordings were obtained from layer $\mathrm{V}$ pyramidal in the mPFC using a

486 MultiClamp 700B Amplifier (Molecular Devices, Sunnyvale, CA). Pyramidal neurons were easily

487 identifiable in the slice based on soma morphology and the presence of a prominent apical

488 dendrite. In the current clamp mode, once a stable membrane potential was observed, intrinsic

489 excitability measurements were performed at the resting membrane potential (RMP). Cell

490 capacitance was measured using the membrane test function in pClamp 10.4 (Molecular

491 Devices, Sunnyvale, CA, USA). All measurements of intrinsic membrane excitability were taken

492 from RMP. Rheobase was measured by applying depolarizing current steps (10 pA steps, 100

493 msec duration) until the generation of a single action potential (AP). Input resistance was

494 measured by applying a hyperpolarizing current step (-20 pA) via the patch electrode. AP

495 threshold was defined as the $V \mathrm{~m}$ measured $0.5 \mathrm{~ms}$ before the peak in the second derivative of

496 the waveform. The action potential threshold and amplitude were analyzed for the first spike at

497 the rheobase current injection. Duration of APs $\left(A P_{50}\right)$ was determined by measuring the

498 elapsed time from the peak of the AP to $50 \%$ maximum amplitude during the repolarization

499 phase. Cells with RMP lower than $-55 \mathrm{mV}$ were included for the final analysis. Outliers were

500 detected using the Grubbs' test (GraphPad Software) and removed from analysis. For AP 1

501 neuron from control and adol CVS+ SPS group; RMP: 1 neuron from control and adol CVS; AP

502 amplitude: 1 neuron from adol CVS group; Membrane resistance: 1 neuron from adol CVS + SPS

503 group; Capacitance: 1 neuron from control and 3 neurons from adol CVS group and for AP 
504 threshold 3 neurons from adol CVS and adol CVS+SPS were removed as outliers. Firing rate was

505 measured in response to $20 \mathrm{pA}$ and $1 \mathrm{sec}$ duration depolarizing current steps in the current

506 clamp configuration. Only cells that produced greater or equal to 5 action potentials for up to

$507240 \mathrm{pA}$ current injection were included in the final analysis. Peak firing frequency was reported

508 as the maximum number of action potentials generated in a given neuron following a current

509 injection step. Number of cells used for electrophysiology are outlined in table 1. Membrane

510 voltages were adjusted for liquid junction potentials (approximately $-14 \mathrm{mV}$ ) calculated using

511 JPCalc software (P. Barry, University of New South Wales, Sydney, Australia; modified for

512 Molecular Devices). Signals were filtered at 4-6 kHz through a $-3 \mathrm{~dB}$, four-pole low-pass Bessel

513 filter and digitally sampled at $20 \mathrm{kHz}$ using a commercially available data acquisition system

514 (Digidata 1550A with pClamp 10.4 software). Data were recorded using pClamp, version 10.4

515 (Molecular Devices) and stored on a computer for offline analysis. Recordings were detected

516 and analysed using Clampfit (Molecular Devices).

\section{$517 \quad$ Statistical analysis}

518 Fear conditioning data were analyzed by repeated measurements ANOVA (adol CVS $x$ SPS $x$ Sex

$519 x$ time), with a level of significance of $p<0.05$. Novel object recognition and Morris water maze

520 data were analyzed by $2 \times 2$ ANOVA (Adol CVS x Sex). Fos data were analyzed by a 2-way ANOVA

521 ( $2 \times 2$ design: adol CVS $\times$ SPS) within each sex with a level of significance $p<0.05$

522 Electrophysiology data were analyzed by $2 \times 2$ ANOVA (adol CVS $\times$ SPS). Details of number of cells

523 used for electrophysiology data analysis are outlined in table 1 . In the cases where significant

524 differences and interactions were found, the Bonferroni test was used for post hoc analysis. In

525 the case there were only main effects of the factors but no significant interaction between 
526 them, we performed planned comparisons to evaluate individual differences. Data were

527 analyzed using STATISTICA 7.0 (Statsoft, Inc.,Tulsa, USA) and Prism 8 (GraphPad Software, La

528 Jolla California USA). Data not following a normal distribution were log transformed for

529 statistical analysis.

530 Table 1.

531 Table depicts number of cells used for the electrophysiology data analysis

\begin{tabular}{|c|c|}
\hline & Number of cells \\
\hline$a$ & $\begin{array}{l}\text { Rheobase was measured in } 19 \text { neurons in the control group, } 17 \text { neurons in } \\
\text { SPS group, } 35 \text { neurons in adolescent stress group, } 31 \text { neurons in } \\
\text { adolescent stress and SPS group } n=2-3 \text { animals/group }\end{array}$ \\
\hline$b$ & $\begin{array}{l}\text { Membrane resistance was measured in } 19 \text { neurons in control group, } 17 \\
\text { neurons in SPS group, } 35 \text { neurons in adolescent stress group and } 30 \\
\text { neurons in the adolescent stress and SPS group } n=2-3 \text { animals/group }\end{array}$ \\
\hline c & $\begin{array}{l}\text { AP threshold was measured in } 19 \text { neurons in control group, } 17 \text { neurons in } \\
\text { SPS group, } 32 \text { neurons in adolescent stress group and } 28 \text { neurons in the } \\
\text { adolescent stress and SPS group } n=2-3 \text { animals/group }\end{array}$ \\
\hline$d$ & $\begin{array}{l}\text { AP amplitude was measured in } 19 \text { neurons in control group, } 17 \text { neurons in } \\
\text { SPS group, } 34 \text { neurons in adolescent stress group and } 31 \text { neurons } \\
\text { adolescent stress and SPS group } n=2-3 \text { animals/group }\end{array}$ \\
\hline e & $\begin{array}{l}\mathrm{AP}_{50} \text { was measured in } 18 \text { neurons in control group, } 17 \text { neurons in SPS } \\
\text { group, } 35 \text { neurons in adolescent stress group and } 30 \text { neurons in the } \\
\text { adolescent stress and SPS group } n=2-3 \text { animals/group }\end{array}$ \\
\hline$f$ & $\begin{array}{l}\text { Resting membrane potential was measured in } 18 \text { neurons in control } \\
\text { group, } 17 \text { neurons in SPS group, } 34 \text { neurons in adolescent stress group and } \\
31 \text { neurons in the adolescent stress and SPS group } n=2-3 \text { animals/group }\end{array}$ \\
\hline g & $\begin{array}{l}\text { Capacitance was measured in } 19 \text { neurons in control group, } 17 \text { neurons in } \\
\text { SPS group, } 32 \text { neurons in adolescent stress group and } 31 \text { neurons in the } \\
\text { adolescent stress and SPS group } n=2-3 \text { animals/group }\end{array}$ \\
\hline $\mathrm{h}$ & $\begin{array}{l}\text { Peak firing frequency was measured in } 11 \text { neurons in control group, } 8 \\
\text { neurons in SPS group, } 5 \text { neurons in adolescent stress group and } 16 \\
\text { neurons in the adolescent stress and SPS group } n=2-3 \text { animals/group }\end{array}$ \\
\hline
\end{tabular}

533 Acknowledgements: The authors would like to thank other members of Dr Herman's laboratory

534 for their assistance in data collection and general discussion of the results. Images were created

535 with BioRender.com. 
537 Funding: This project was funded by the National Institutes of Health (R01MH101729, R01

MH049698 and R01 MH119814 to JPH, T32 DK059803 to EMC and SEM, F31MH123041 to NN),

U.S. Department of Veterans Affairs (Grant I01BX003858 to JPH), NARSAD Young Investigator

540 Award from the Brain and Behavior Research Foundation to RDM, Cohen Veterans Bioscience:

541 Preclinical Grants Program (AMP-IT-UP) to SEM.

543 Competing Interests: The authors declare that this study was conducted in the absence of any

544 financial or commercial relationships that could be considered as a potential conflict of interest.

\section{References}

547 Andersen SL, Teicher MH. 2008. Stress, sensitive periods and maturational events in adolescent depression. Trends Neurosci 31:183-91. doi:10.1016/j.tins.2008.01.004

549 Anderson EM, Gomez D, Caccamise A, McPhail D, Hearing M. 2019. Chronic unpredictable stress promotes cell-specific plasticity in prefrontal cortex D1 and D2 pyramidal neurons.

Bagley J, Moghaddam B. 1997. Temporal dynamics of glutamate efflux in the prefrontal cortex and in the hippocampus following repeated stress: Effects of pretreatment with saline or diazepam: Neuroscience 77:65-73. doi:10.1016/S0306-4522(96)00435-6 subpopulations of deep-layer pyramidal neurons in the neocortex: Bridging cellular properties to functional consequences. J Neurosci 38:5441-5455. 
Begni V, Zampar S, Longo L, Riva MA. 2020. Sex Differences in the Enduring Effects of Social Deprivation during Adolescence in Rats: Implications for Psychiatric Disorders. Neuroscience 437:11-22. doi:10.1016/j.neuroscience.2020.04.018

Benjet C, Bromet E, Karam EG, Kessler RC, McLaughlin KA, Ruscio AM, Shahly V, Stein DJ, Petukhova M, Hill E, Alonso J, Atwoli L, Bunting B, Bruffaerts R, Caldas-de-Almeida JM, de Girolamo G, Florescu S, Gureje O, Huang Y, Lepine JP, Kawakami N, Kovess-Masfety V, Medina-Mora ME, Navarro-Mateu F, Piazza M, Posada-Villa J, Scott KM, Shalev A, Slade T, ten Have M, Torres Y, Viana MC, Zarkov Z, Koenen KC. 2016. The epidemiology of traumatic event exposure worldwide: results from the World Mental Health Survey Consortium. Psychol Med 46:327-43. doi:10.1017/S0033291715001981

Blouin AM, Sillivan SE, Joseph NF, Miller CA. 2016. The potential of epigenetics in stressenhanced fear learning models of PTSD. Learn Mem 23:576-86. doi:10.1101/Im.040485.115

Bourke CH, Neigh GN. 2011. Behavioral effects of chronic adolescent stress are sustained and sexually dimorphic. Horm Behav 60:112-120. doi:10.1016/J.YHBEH.2011.03.011

Chaby LE, Sadik N, Burson NA, Lloyd S, O'Donnel K, Winters J, Conti AC, Liberzon I, Perrine SA. 2020. Repeated stress exposure in mid-adolescence attenuates behavioral, noradrenergic, and epigenetic effects of trauma-like stress in early adult male rats. Sci Rep 10:17935. doi:10.1038/s41598-020-74481-3

Cotella EM, Morano RL, Wulsin AC, Martelle SM, Lemen P, Fitzgerald M, Packard BA, Moloney RD, Herman JP. 2020. Lasting Impact of Chronic Adolescent Stress and Glucocorticoid Receptor Selective Modulation in Male and Female Rats. Psychoneuroendocrinology 
112:104490. doi:10.1016/j.psyneuen.2019.104490

582

Cotella EM, Scarponi Gómez A, Lemen P, Chen C, Fernández G, Hansen C, Herman JP, Paglini

MG. 2019. Long-term impact of chronic variable stress in adolescence versus adulthood.

Prog Neuro-Psychopharmacology Biol Psychiatry 88:303-310.

Covington HE, Lobo MK, Maze I, Vialou V, Hyman JM, Zaman S, LaPlant Q, Mouzon E, Ghose S,

de Kloet ER, Joëls M, Holsboer F. 2005. Stress and the brain: from adaptation to disease. Nat

Deng JH, Yan W, Han Y, Chen C, Meng SQ, Sun CY, Xu LZ, Xue YX, Gao XJ, Chen N, Zhang FL,

Friedman AK, Walsh JJ, Juarez B, Ku SM, Chaudhury D, Wang J, Li X, Dietz DM, Pan N, Vialou VF,

599 Giustino TF, Maren S. 2015. The Role of the Medial Prefrontal Cortex in the Conditioning and

$600 \quad$ Extinction of Fear. Front Behav Neurosci 9. doi:10.3389/fnbeh.2015.00298

601 Green MR, Barnes B, Mccormick CM. 2013. Social instability stress in adolescence increases 
Psychobiol 55:849-859. doi:10.1002/dev.21077

604 Hains AB, Arnsten AFT. 2008. Molecular mechanisms of stress-induced prefrontal cortical impairment: implications for mental illness. Learn Mem 15:551-64. doi:10.1101/Im.921708

Han MH, Nestler EJ. 2017. Neural Substrates of Depression and Resilience. Neurotherapeutics. doi:10.1007/s13311-017-0527-x

Hearing M, Kotecki L, MarronFernandezdeVelasco E, Fajardo-Serrano A, Chung HJ, Luján R, Wickman K. 2013. Repeated Cocaine Weakens GABAB-Girk Signaling in Layer 5/6 Pyramidal Neurons in the Prelimbic Cortex. Neuron 80:159-170. doi:10.1016/j.neuron.2013.07.019 trauma and depression: Insights from HPA axis studies in humans. Psychoneuroendocrinology 33:693-710. doi:10.1016/J.PSYNEUEN.2008.03.008

616 Herring MP, O'Connor PJ, Dishman RK. 2010. The effect of exercise training on anxiety symptoms among patients: A systematic review. Arch Intern Med. doi:10.1001/archinternmed.2009.530

Ishikawa J, Nishimura R, Ishikawa A. 2015. Early-life stress induces anxiety-like behaviors and 620 activity imbalances in the medial prefrontal cortex and amygdala in adult rats. Eur J Neurosci 41:442-453. doi:10.1111/ejn.12825

622 Jackson ME, Moghaddam B. 2006. Distinct patterns of plasticity in prefrontal cortex neurons 623 that encode slow and fast responses to stress. Eur J Neurosci 24:1702-1710. 
625 Jackson ME, Moghaddam B. 2004. Stimulus-specific plasticity of prefrontal cortex dopamine neurotransmission. J Neurochem 88:1327-1334. doi:10.1046/j.1471-4159.2003.02205.x

627 Jankord R, Solomon MB, Albertz J, Flak JN, Zhang R, Herman JP. 2011. Stress vulnerability during

628 adolescent development in rats. Endocrinology 152:629-38. doi:10.1210/en.2010-0658

629 Johnson DC, Casey BJ. 2014. Easy to remember, difficult to forget: The development of fear

$630 \quad$ regulation. Dev Cogn Neurosci. doi:10.1016/j.den.2014.07.006

631 Kendig MD, Bowen MT, Kemp AH, McGregor IS. 2011. Predatory threat induces huddling in Behav Brain Res 225:405-414. doi:10.1016/j.bbr.2011.07.058

634 Kessler RC, Berglund P, Demler O, Jin R, Merikangas KR, Walters EE. 2005. Lifetime Prevalence and Age-of-Onset Distributions of DSM-IV Disorders in the National Comorbidity Survey

Knox D, George SA, Fitzpatrick CJ, Rabinak CA, Maren S, Liberzon I. 2012a. Single prolonged stress disrupts retention of extinguished fear in rats. Learn Mem 19:43-9.

640 Knox D, Nault T, Henderson C, Liberzon I. 2012b. Glucocorticoid receptors and extinction retention deficits in the single prolonged stress model. Neuroscience 223:163-173.

643 Kohda K, Harada K, Kato K, Hoshino A, Motohashi J, Yamaji T, Morinobu S, Matsuoka N, Kato N. 644 2007. Glucocorticoid receptor activation is involved in producing abnormal phenotypes of 645 single-prolonged stress rats: A putative post-traumatic stress disorder model. 
647 Kumar S, Hultman R, Hughes D, Michel N, Katz BM, Dzirasa K. 2014. Prefrontal cortex reactivity underlies trait vulnerability to chronic social defeat stress. Nat Commun 5:4537. doi:10.1038/ncomms5537

650 Liberzon I, Krstov M, Young EA. 1997. Stress-restress: Effects on ACTH and fast feedback. Psychoneuroendocrinology 22:443-453. doi:10.1016/S0306-4530(97)00044-9

652 Liberzon I, Ló Pez JF, Flagel SB, Vá Zquez DM, Young EA. 1999. Differential Regulation of Hippocampal Glucocorticoid Receptors mRNA and Fast Feedback: Relevance to PostTraumatic Stress Disorder, Journal of Neuroendocrinology.

Lukkes JL, Mokin M V, Scholl JL, Forster GL. 2009. Adult rats exposed to early-life social isolation exhibit increased anxiety and conditioned fear behavior, and altered hormonal stress responses. Horm Behav 55:248-56. doi:10.1016/j.yhbeh.2008.10.014

Matovic S, Ichiyama A, Igarashi H, Salter EW, Sunstrum JK, Wang XF, Henry M, Kuebler ES, Vernoux N, Martinez-Trujillo J, Tremblay M, Inoue W. 2020. Neuronal hypertrophy dampens neuronal intrinsic excitability and stress responsiveness during chronic stress. $J$

McEwen BS. 2007. Physiology and neurobiology of stress and adaptation: central role of the brain. Physiol Rev 87:873-904. doi:10.1152/physrev.00041.2006

Meir Drexler S, Wolf OT. 2017. The role of glucocorticoids in emotional memory reconsolidation. Neurobiol Learn Mem. doi:10.1016/j.nlm.2016.11.008 
Milad MR, Pitman RK, Ellis CB, Gold AL, Shin LM, Lasko NB, Zeidan MA, Handwerger K, Orr SP,

Posttraumatic Stress Disorder. Biol Psychiatry 66:1075-1082. doi:10.1016/j.biopsych.2009.06.026

Milad MR, Quirk GJ. 2002. Neurons in medial prefrontal cortex signal memory for fear extinction. Nature 420:70-74. doi:10.1038/nature01138

Milad MR, Rauch SL, Pitman RK, Quirk GJ. 2006. Fear extinction in rats: Implications for human brain imaging and anxiety disorders. Biol Psychol 73:61-71.

Moore NLT, Gauchan S, Genovese RF. 2014. Adolescent traumatic stress experience results in less robust conditioned fear and post-extinction fear cue responses in adult rats.

Negrón-Oyarzo I, Pérez MÁ, Terreros G, Muñoz P, Dagnino-Subiabre A. 2014. Effects of chronic stress in adolescence on learned fear, anxiety, and synaptic transmission in the rat

Novick AM, Mears M, Forster GL, Lei Y, Tejani-Butt SM, Watt MJ. 2016. Adolescent social defeat Pharmacol Biochem Behav 120:17-24. doi:10.1016/j.pbb.2014.01.011

687 Oitzl MS, Champagne DL, van der Veen R, de Kloet ER. 2010. Brain development under stress:

688 Hypotheses of glucocorticoid actions revisited. Neurosci Biobehav Rev 34:853-866. doi:10.1016/j.neubiorev.2009.07.006 
cortex of rats, monkeys and humans. Cereb Cortex. doi:10.1093/cercor/10.3.206

Ordoñes Sanchez E, Bavley CC, Deutschmann AU, Carpenter R, Peterson DR, Karbalaei R,

Ozbay F, Johnson DC, Dimoulas E, Morgan CA, Charney D, Southwick S. 2007. Social support and resilience to stress: from neurobiology to clinical practice. Psychiatry (Edgmont) 4:35-40.

Paus T, Keshavan M, Giedd JN. 2008. Why do many psychiatric disorders emerge during adolescence? Nat Rev Neurosci 9:947-957. doi:10.1038/nrn2513

Paxinos G, Watson C. 2007. The rat brain in stereotaxic coordinates. Elsevier.

Piggott VM, Bosse KE, Lisieski MJ, Strader JA, Stanley JA, Conti AC, Ghoddoussi F, Perrine SA. 2019. Single-prolonged stress impairs prefrontal cortex control of amygdala and striatum

Rauch SL, Shin LM, Phelps EA. 2006. Neurocircuitry Models of Posttraumatic Stress Disorder and

Riboni FV, Belzung C. 2017. Stress and psychiatric disorders: from categorical to dimensional approaches. Curr Opin Behav Sci. doi:10.1016/j.cobeha.2016.12.011

711 Ricon T, Toth E, Leshem M, Braun K, Richter-Levin G. 2012. Unpredictable chronic stress in 712 juvenile or adult rats has opposite effects, respectively, promoting and impairing 
resilience. Stress 15:11-20. doi:10.3109/10253890.2011.572207

714 Romeo RD. 2015. Perspectives on stress resilience and adolescent neurobehavioral function. Neurobiol Stress. doi:10.1016/j.ynstr.2014.11.001

Russo SJ, Murrough JW, Han MH, Charney DS, Nestler EJ. 2012. Neurobiology of resilience. Nat Neurosci. doi:10.1038/nn.3234

Sareen J. 2014. Posttraumatic stress disorder in adults: Impact, comorbidity, risk factors, and treatment. Can J Psychiatry 59:460-467. doi:10.1177/070674371405900902

Schmidt M. 2011. Animal models for depression and the mismatch hypothesis of disease.

Shah MM. 2014. Cortical HCN channels: Function, trafficking and plasticity. J Physiol 592:27112719. doi:10.1113/jphysiol.2013.270058

724 Southwick SM, Charney DS. 2012. The Science of Resilience: Implications for the Prevention and

725 Treatment of Depression. Science (80- ) 338:79-82. doi:10.1126/science.1222942

726 Suo L, Zhao L, Si J, Liu J, Zhu W, Chai B, Zhang Y, Feng J, Ding Z, Luo Y, Shi H, Shi J, Lu L. 2013.

727 Predictable chronic mild stress in adolescence increases resilience in adulthood. Neuropsychopharmacology 38:1387-1400. doi:10.1038/npp.2013.67

729 Ting JT, Daigle TL, Chen Q, Feng G. 2014. Acute brain slice methods for adult and aging animals:

730 Application of targeted patch clamp analysis and optogenetics. Methods Mol Biol

731 1183:221-242. doi:10.1007/978-1-4939-1096-0_14

732 Tost H, Champagne FA, Meyer-Lindenberg A. 2015. Environmental influence in the brain, 733 human welfare and mental health. Nat Neurosci. doi:10.1038/nn.4108

734 Tsoory MM, Guterman A, Richter-Levin G. 2010. “Juvenile stress" alters maturation-related 
changes in expression of the neural cell adhesion molecule L1 in the limbic system:

Relevance for stress-related psychopathologies. J Neurosci Res 88:369-380. doi:10.1002/jnr.22203

Vyas A, Mitra R, Shankaranarayana Rao BS, Chattarji S. 2002. Chronic stress induces contrasting patterns of dendritic remodeling in hippocampal and amygdaloid neurons. J Neurosci 22:6810-8. doi:20026655

741 Wen L, Han F, Shi Y. 2015. Changes in the Glucocorticoid Receptor and Ca2+/CalreticulinDependent Signalling Pathway in the Medial Prefrontal Cortex of Rats with Post-traumatic Stress Disorder. J Mol Neurosci 56:24-34. doi:10.1007/s12031-014-0464-7

744 Wilkin MM, Waters P, McCormick CM, Menard JL. 2012. Intermittent physical stress during early- and mid-adolescence differentially alters rats' anxiety- and depression-like behaviors in adulthood. Behav Neurosci 126:344-360. doi:10.1037/a0027258

747 Wulsin AC, Wick-Carlson D, Packard BA, Morano R, Herman JP. 2016. Adolescent chronic stress doi:10.1016/j.psyneuen.2015.12.004

751 Yee N, Schwarting RKW, Fuchs E, Wöhr M. 2012. Juvenile stress potentiates aversive 22-kHz 752 ultrasonic vocalizations and freezing during auditory fear conditioning in adult male rats. Stress 15:533-544. doi:10.3109/10253890.2011.646348 